\title{
Dislexia: Leitura e Escrita numa Perspectiva Bibliográfica
}

\author{
Maria Zuleide de Lima Nogueira ${ }^{1}$; Theóphilo Michel Álvares Cabral Beserra ${ }^{2}$
}

\begin{abstract}
Resumo: Este artigo científico centrou, através do levantamento bibliográfico, compreender a Dislexia na perspectiva psicopedagógica, para após o estudo entender como acontece a síndrome durante a infância, uma vez que a dislexia só pode ser identificada, logo que se inicia o processo de alfabetização, embora que os estudos, também, mostram que essas características podem acontecer na fase adulta, onde o individuo passou toda a sua infância-adolescência sem saber que era acometido pela dislexia. Para fundamentar o estudo, optou-se pelos levantamentos teóricos de autores que discernem sobre o assunto. O processo de aprendizagem da leitura é um fator desafiador, uma vez que ela faz parte do avanço do educando não só em língua portuguesa, mas também nas outras disciplinas, desde a simples assinatura de seu nome à construção frasal mais complexa. A não aprendizagem da leitura pelo aluno, à certo tempo, era caracterizado como aluno inapto a ler, o qual era encaminhado pelos pais e profissionais a outras atividades que não envolvessem a leitura, e taxado como " esse menino não dá para leitura". A descoberta da Dislexia possibilitou novos olhares para esse educando, e possibilitou uma nova forma de aprender a ler e escrever para eles. O estudo é puramente bibliográfico, sua pesquisa teórica embasou em livros, artigos e site do Google profissional da internet.
\end{abstract}

Palavras - Chave: Dislexia. Leitura. Alfabetização. Linguagem. Adquirida. Desenvolvimento.

\section{Dyslexia: \\ Reading and Writing in a Bibliographic Perspective}

\begin{abstract}
This scientific article focused through the literature, understand the Dyslexia psychoeducational perspective, for after the study to understand as it is the syndrome during childhood, since that dyslexia can be identified as soon as it starts the process of literacy, although that studies also show that these characteristics may occur in adulthood where the individual has spent his entire childhood, adolescence without knowing that it was affected by dyslexia. To support the study, it was decided by the theoretical surveys of authors who discerned on the subject. The process of learning to read is a challenging factor, since it is part of the student's progress not only in English but also in other disciplines, from the simple signing his name to the more complex phrasal construction. Failure to learning to read by the student, for some time, was characterized as a student unable to read, which was forwarded by parents and professionals to other activities that do not involve reading, and taxed as "that boy you can not read." The discovery of dyslexia possible new looks for that student, and made possible a new way of learning to read and write to them. The study is purely bibliographical, theoretical research based in part on his books, articles and professional Google's internet site.
\end{abstract}

Key - words: Dyslexia. Reading. Literacy. Language. Acquired. Development

\footnotetext{
1 Mestranda em Educação - Programa de Mestrado Internacional em Educação Anne Sullivan University - zuleide.lima01@ hotmail.com; ${ }^{2}$ Mestre em Geografia pela Universidade Federal do Ceará, Especialista em Geografia e Meio Ambiente pela Universidade Regional do Cariri, licenciado em geografia pela Universidade Regional do Cariri. Atualmente é membro do Conselho Municipal de Defesa do Meio Ambiente de Juazeiro do Norte - Ceará - COMDEMA, membro do Comitê Institucional de Avaliação do Programa de Bolsas de Iniciação Científica e Tecnológica do Instituto CENTEC, Conselheiro do Eixo Tecnológico Ambiente e Saúde da Faculdade de Tecnologia CENTEC, FATECCARIRI, membro do Núcleo Docente Estruturante do Eixo Tecnológico Ambiente e Saúde e representante docente eleito para o Conselho de Administração do Instituto CENTEC junto a Secretaria da Ciência, Tecnologia e Educação Superior do Estado do Ceará - SECITECE. Professor do eixo tecnológico ambiente e saúde. E-mail: mic.beserra@hotmail.com.
} 
Id on Line Revista Multidisciplinar e de Psicologia

Id on Line Multidisciplinary and Psycology Journal

\section{Introdução}

Este artigo trata de uma revisão da literatura, perfazendo os conceitos de dislexias e suas manifestações em criança na fase do processo ensino-aprendizagem. Para tanto a pesquisa fundamentou-se nas publicações de autores que discutem o assunto.

A pesquisa bibliográfica se utiliza fundamentalmente das contribuições dos diversos autores sobre a Dislexia. Caracteriza-se pela identificação e análise da dislexia através de escritos em livros, artigos de revistas e sites da internet, dentre sua finalidade é colocar o investigador em contato com o que já se produziu a respeito da Dislexia.

A dislexia pode prejudicar educando acometidos por ela, causando a ele, sérios problemas de aprendizagem. Tais problemas podem ser fatais na vida escolar de nossos educandos.

O fracasso escolar tem sido motivo de estudos entre especialistas e muitos outros educadores que se preocupam com a realidade das crianças que passam por esses problemas de aprendizagem.

Sabe-se que, quando uma criança não desenvolve na escola, também, não desenvolve a convivência com seus colegas e professores. Pois, a sensação de fracasso escolar ocasiona na criança um certo desequilíbrio, que faz com que ela pense que é inferior aos seus coleguinhas, ou ainda que é incapaz de aprender. E tal sensação pode prosseguir por toda sua vida.

Para Mônica Abud Perez de Cerqueira Luz:

As dificuldades de leitura produzem complicações na aprendizagem escolar e muitas vezes inibe ou impede a criança a se desenvolver plenamente do ponto de vista intelectual, social e emocional. A leitura não constitui uma habilidade isolada; pelo contrário, faz parte de um processo lingüístico bastante complexo. Assim, a dificuldade em exercê-la mostra uma deficiência na estrutura e/ou na organização da linguagem em geral. (LUZ, 2010, p.7)

Neste sentido compreende-se que a leitura é fundamental para o desenvolvimento do aluno, não apenas nas disciplinas ligadas a leitura, mas também, em todas as demais disciplinas. E que a leitura estará presente durante toda a vida do aluno, seja dentro ou fora dos muros da escola. "A dificuldade para ler é reconhecida como uma das causas determinantes do fracasso escolar e de exclusão social. O leitor deficiente não consegue captar e nem mesmo interpretar os símbolos verbais impressos" (LUZ, 2010, p.7). A pesquisa foi desenvolvida nesta 
Id on Line Revista Multidisciplinar e de Psicologia

Id on Line Multidisciplinary and Psycology Journal

perspectiva, a de que a leitura é imprescindível para o desenvolvimento de outras habilidades educacionais.

Ler, segundo Lacombe (1999) apud Veras (2007), é adentrar no universo cultural de um mundo específico. Quando a criança começa a ler só decodifica o existente, como inicia o seu processo de inserção de um universo de compreensão de mundo diferenciado e com características próprias. Daí a imensa importância da aquisição da leitura.

No decorrer da revisão bibliográfica encontram-se algumas das principais dificuldades de leitura e escrita causada pela dislexia. Deste modo, descobrir o quanto a leitura é importante na vida do educando e a partir daí compreender que é fundamental conhecer as causas para minimizar danos causados pela dislexia.

\section{A Dislexia}

Entende-se por dislexia especifica ou dislexia de evolução um conjunto de sintomas reveladores de uma disfunção parietal (o lado do cérebro onde fica o centro nervoso da escrita), geralmente hereditária, ou às vezes adquirida, que afeta a aprendizagem da leitura num contínuo que se estende do leve sintoma aos sintomas grave. A dislexia é frequentemente acompanhada de transtornos da aprendizagem da escrita, ortografia, gramática e redação. A origem da dislexia, de acordo com Ballone (2001) apud Evans (2006, p. 4), "fundamenta-se no eixo corporal, na base psicomotora, e se desenvolve anteriormente à escrita". A dislexia afeta os meninos em uma proporção maior do que as meninas.

Segundo Cassiano (2004, p. 23):

A dislexia é uma dificuldade particular para identificar, compreender e reproduzir os símbolos escritos, que apresenta como consequencia uma alteração profunda da aprendizagem da leitura entre 5 e os 8 anos, na ortografia, na compreensão de textos e, portanto, nas aquisições escolares.

Visto assim, que o termo dislexia se refere a um distúrbio de aprendizagem que atinge crianças com dificuldades especificas de leitura e escrita. Essas crianças são incapazes de ler com a mesma facilidade que seus colegas da mesma idade, embora possuam inteligência normal, saúde e órgãos sensórias perfeitos, estejam em estado emocional considerado normal, 
Id on Line Revista Multidisciplinar e de Psicologia

Id on Line Multidisciplinary and Psycology Journal

tenham motivação normal e instrução adequada.

Segundo Critchey apud Cassiano (2004, p. 23): “(...) a dislexia trata-se de uma perturbação que se manifesta na dificuldade em aprender a ler, apesar de o ensino ser convencional, a inteligência adequada, as oportunidades socioculturais suficientes".

$\mathrm{Na}$ dislexia em geral, a dificuldade de leitura persiste até a idade adulta. A dificuldade de ortografia geralmente acompanha a de leitura, o que é compreensível por serem habilidades relacionadas. Muitas pessoas aparentemente normais, ou mesmo com grande capacidade de leitura, podem apresentar dificuldade de ortografia. Até mesmo, professores podem apresentar esse problema.

A dificuldade de leitura pode aparecer em qualquer idade, porém quase todas as pesquisas existentes foram em crianças. A capacidade de ler está intimamente ligada aos seguintes fatores:

- Noção de esquema corporal (conhecimento das partes do corpo);

- Orientação no tempo e no espaço (sucessão de acontecimento ou evento);

- Linguagem e conhecimento do código linguístico (conhecimento das letras, dos sinais);

- Fatores ambientais que acompanham todos os outros;

- O disléxico tem geralmente a seguinte história de vida.

1) Algum parente próximo com a mesma deficiência de linguagem.

2) Nasceu provavelmente de um parto difícil, em que pode ter ocorrido algum destes problemas:

- Anóxia, ou seja, asfixia relativa;

- Prematuridade, ou seja, o crescimento passou da data prevista para o parto;

3) Adquiriu, quando criança, alguma doença infectocontagiosa, que tenha produzido convulsões ou perda de consciência.

4) Atraso na aquisição da linguagem ou perturbações na articulação da mesma.

5) Atraso para andar.

6) Problemas de dominância lateral (uso retardado da mão esquerda ou direita). (VERAS, 2007, p. 11)

Para Orton apud Cassiano (2004, p. 24), a dislexia seria explicada por uma inadequada 
instalação da dominância lateral (lateralidade). Orton inspirou-se nos trabalhos de Broca (o mesmo que descreveu o centro da articulação da palavra em 1865). Em sua tese, Broca admite que o predomínio funciona de um lado do corpo se deve não à educação, mas sim a supremacia de um hemisfério cerebral sobre o ouro. "É de conhecimento de profissionais da área que a criança para aprender a ler necessita da consciência de seu eixo corporal, seu lado direito e esquerdo etc., (...)". (EVANS, 2006, p.6). A escrita em espelho, o retardo da linguagem e a gagueira são também explicáveis por esse conflito de dominância dos hemisférios cerebrais por muitos autores.

\section{Alguns Erros de Leitura e Escrita encontrados na Dislexia}

Durante a pesquisa percebe-se que existem outros fatores que podem influencia na não assimilação da leitura e escrita. De acordo Mônica Abud Perez de Cerqueira Luz:

Trata-se de uma dificuldade significativa somente no desenvolvimento das habilidades relacionadas com a escrita propriamente. A gravidade do problema pode ir de erros na soletração até em erros na síntese; estrutura; pontuação; paragrafação. É importante salientar que existem processos cognitivos envolvidos na escrita: processo de planejamento da mensagem; construção sintática; recuperação de elementos léxicos e processos motores que culminariam com a produção da escrita de forma aberta. A escrita é um processo complexo; de construção e que não culmina com aquisição dos simples automatismos gráficos. (LUZ, 2010, p. 7)

No trato com a dislexia persistem algumas dificuldades próprias da síndrome como:

- Confusão de letras, sílabas ou palavras com pequenas diferenças de grafia: a/o, c/o, e/f, etc.

- Confusão de letras, sílabas ou palavras com grafia semelhante, porém com orientação especial diferente: $b / d, p / b, b / q$, etc.

- Confusão de letras que possuem sons parecidos: b/d, p/q, b/q, etc.

- Confusão de letras que possuem sons parecidos: b/d, p/q, d/t, m/b, etc.

- Inversão parcial ou total de sílabas ou palavras: me em vez de em sol em vez de los, som em vez de mos, etc.

- Substituição de palavras por outras estruturas mais ou menos semelhantes: salvou no 
Id on Line Revista Multidisciplinar e de Psicologia

Id on Line Multidisciplinary and Psycology Journal

lugar de saltou, sentiu no lugar de mentiu.

- Contaminação de sons: latito em vez de palito.

- Adição ou omissão de sons, sílabas ou palavras; casa em vez de casaco, neca em vez de boneca, etc.

- Repetição de sílabas, palavras: casa em vez de casaco, neca em vez de boneca, etc.

- Repetição de sílabas, palavras ou frases: macaco, paipai.

- Saltou de linha, volta à linha anterior e perda da linha durante a leitura.

- Acompanhamento com o dedo da linha que está sendo lida.

- Leitura do texto palavra por palavra.

- Problemas de compreensão do texto.

- Escrita em espelho (em sentido inverso ao normal)

- Letra ilegível;

- Leitura analítica e decifratória. Quando lê silenciosamente, a criança não consegue deixar de murmurar ou mover os lábios, pois precisa pronunciar as palavras para entender o seu significado. (VERAS, 2007, p. 13)

Veras (2007), através de técnicas terapêuticas, a maioria dos disléxicos pode melhorar o seu grau de dificuldade. Para isso, porém, deverá se esforçar muito. Grande parte dos disléxicos não tem gosto pela leitura, nem é capaz de dominar a leitura e a ortografia de uma segunda língua (língua estrangeira).

Se o disléxico não for submetido a uma instrução especializada, pode permanecer analfabeto. Geralmente os disléxicos ficam excluídos das profissões e vocações que exigem uma preparação acadêmica.

\section{A Disléxica numa Abordagem Neuropsicológica}

Sabe-se que a leitura é um processo perceptivo-linguistico muito complexo, refinado para uma série de atos automáticos que rapidamente são integrados psicologicamente para produzir pensamentos e comportamentais significativos. "Porém, o processo de leitura em si varia de pessoas para pessoa, dependendo de fatores como idade e maturação, sexo, 
hereditariedade, experiências cultural, instrução, prática e motivação". (VERAS, 2007, p. 13)

Existem muitas habilidades intrínsecas a leitura, mas a maioria destas estão baseadas em destrezas perceptivas - lingüísticas fundamentais, tais como integração auditivo-visual e ordenação. É exatamente nestas habilidades que a pessoas disléxicas é mais deficiente.

Segundo Cassiano (2004, p. 40) apud (VERAS, 2007, p. 14):

\begin{abstract}
De acordo com o trabalho publicado pelo médico Orton, em 1928, muitas crianças com graves inabilidades para leitura faziam inversões e imagem espetacular de letras e palavras, concluindo que tais fenômenos eram provocados por imagens competitivas nos dois hemisférios cerebrais devido à falência em estabelecer dominância cerebral unilateral e consistência perceptiva. Denominou esta condição de estrefossimbolia (símbolos invertidos), sendo até hoje aceita como um dos principais sinais de diagnósticos de dislexia.
\end{abstract}

Essa imaturidade provocará o fracasso na compatibilidade de letras e palavras com suas correspondentes formas faladas, sendo evidenciadas por rotações e inversões, omissões e substituições, problemas de pronúncia e análise estrutural e subseqüentes dificuldades em compreensão.

Veras (2007), as inaptidões comportamentais de crianças disléxicas foram pesquisadas por vários cientistas, onde concluíram que o retardamento da dominância cerebral e os distúrbios de linguagem podem refletir atraso de maturação ou distúrbios de linguagem podem refletir atraso de maturação ou disfunção, assim sendo, a educação formal para a leitura deveria ser adiada para essas crianças, até que fossem alcançadas sucesso com instrução perceptivomotora e com linguagem oral.

A dislexia é distúrbios que interfere com a integração significativa de símbolos lingüísticos e perceptivos e se originaram de disfunção ou imaturidade neuropsicológica. Este distúrbio evidencia-se como imaturidade grosseira das habilidades psicolingüísticas e de prontidão para leitura, em crianças em idade pré escolar e com inteligência normal, uma defasagem de dois ou mais anos, associados a habilidades lingüísticas - perceptivas, frequentemente são sinais de condições de dislexia. "A dislexia é considerada um distúrbio específico da linguagem, que tem como característica principal a dificuldade de um aluno em decodificar ou compreender palavras" (EVANS, 2006, p. 6)

O quadro de dislexia pode ser diagnosticado e tratado através de intervenção prematura e tratamento adequado. $\mathrm{O}$ tratamento inicial consiste em ensino diagnostico - prescritivo que, focaliza a disfunção neuropsicológica em processo, através do uso de técnicas e metodologias 
Id on Line Revista Multidisciplinar e de Psicologia

Id on Line Multidisciplinary and Psycology Journal

instrucionais especiais.

Segundo Cassiano (2004, p. 34): Em pesquisas realizadas pelo neurologista inglês Critchley, 1970, concluiu-se que:" o ponto de vista comumente mantido pela maioria dos neurologistas é que a ambilateralidade como a dislexia são expressões de um fator comum, denominado de imaturidade das funções cerebrais". "A suspeita da origem neurobiológica da dislexia surgiu em 1891 quando uma neurologista francesa chamada Djerine sugeriu que a parte posterior do lado esquerdo do cérebro era crítica para a leitura". (EVANS, 2006, p.7)

Um dos estudos mais completos, sendo considerado um marco em pesquisas estatísticas sobre a síndrome disléxica foi realizada pelo psicólogo Kassen (1972). Neste estudo emergiu o quadro dos dados de dislexia como uma dificuldade complexa de disfunções comportamentais associadas, (VERAS, 2007, p. 15):

\footnotetext{
$\checkmark \quad 67,27 \%$ do grupo com problemas visuais e visual-motor;

$\checkmark \quad 66 \%$ com sinais claros de disfunção cerebral mínima;

$\checkmark \quad 65 \%$ com lateralidade mista (dominância cruzada);

$\checkmark \quad 39,7 \%$ tinham parentes próximos com distúrbios de aprendizagem;

$\checkmark \quad 39,6 \%$ demonstravam aquisição tardia de fala, aos 18 meses de idade;

$\checkmark \quad 39,3 \%$ evidenciavam hábitos nervosos como roer unhas, tiques, enurese;

$\checkmark$ 33,2\% apresentavam retardo de manutenção ou de desenvolvimento;

$\checkmark \quad$ 26,8 havíamos sido taxados como hiperativo ou impulsivo;

$\checkmark \quad 22,4 \%$ tinham impedimentos de fala tais como articulação pobre;

$\checkmark \quad 18,4 \%$ eram hipoativos com resposta.
}

\section{Dislexias Adquiridas}

Cada vez mais especialistas distinguem entre os tipos de dislexia adquirida como: profunda, superficial, central, semântica e visual. Para Mariana Almeida (2002) apud (EVANS, 2006, p.10), existem três tipos de dislexia:

(...) a acústica que surge com a insuficiência para a diferenciação acústica dos fonemas e na análise bem como na síntese destes, proporcionando alterações de fonemas. Nesse caso o aluno confunde os fonemas através de sua semelhança articulatória. O segundo tipo, visual, manifesta-se quando ocorre coordenação viso-espacial imprecisa e aparece quando o aluno confunde as letras de maior semelhança gráfica, o que faz com que na maioria das vezes os alunos 10 sejam encaminhados a oftalmologistas. E por último, o tipo motriz, que aparece na dificuldade da criança em seu movimento ocular, ocorrendo uma limitação bastante caracterizada do campo visual que gera atrasos e falhas ao ler. 
Id on Line Revista Multidisciplinar e de Psicologia

Id on Line Multidisciplinary and Psycology Journal

Para (Citoler, 1996 cit. Cruz, 1999), Bautista (1997) apud (MARQUES, 2014, p. 32):

A dislexia classifica-se em dois tipos distintos: dislexias adquiridas e dislexias evolutivas ou desenvolvimentais, (...) explica que dislexia adquirida atribui-se aos indivíduos que já tinham adquirido a capacidade de leitura e vieram a perdê-la em consequência de uma lesão cerebral; a dislexia evolutiva atribui-se quando essa aquisição se faz mais lentamente ou é incompleta.

Em todos os casos da dislexia adquirida, os especialistas contam como sinais diretos ou indiretos que reforçam a opinião de que tais dificuldades são causadas em parte por dano cerebral. Os sinais direitos, por exemplos, dano físico ou lesão cerebral, e as evidencias reveladas por uma operação ou autopsia, ou quaisquer outros métodos que mostrem que podem existir lesões cerebrais ou hemorragias, como numa embolia. Os sinais indiretos consistem em padrões irregulares no exame eletroencefalográfico (EEG); reflexos anormais, ou dificuldades na coordenação e orientação olho/mão e na lateralidade.

Veras (2007), na dislexia a visual, a criança apresenta dificuldade em seguir e reter sequencias visuais e na análise e integração visual de quebra-cabeças e tarefas similares. Também apresenta freqüentes reversões e inversões de letras, confundindo com facilidades palavras e letras. Por meio de exercícios adequados pode-se aprender os signos $\mathrm{f}$ gráficos com precisão e gradualmente aprender sequencias, porém a lentidão pode persistir. A dificuldade auditiva gera o desconforto na diferenciação de sons, reforçando ainda mais o trabalho da aprendizagem, para Veras (2007, p. 16):

$\mathrm{Na}$ dislexia auditiva encontramos dificuldades significativas na discriminação de letras reconhecimento de sons, palavras compostas e na memória de sequencia de sons de letras e palavras, instruções e história. Esta é a forma de dislexia mais difícil de corrigir e radica na inabilidade em perceber os sons separados (descontínuos) da linguagem oral. A maioria dos disléxicos auditivos apresenta audição normal. A dificuldade na discriminação auditiva gera alterações no ditado e composição.

Veras (2007), o ensino da fonética tradicional carece de sentido para eles. Também apresentam dificuldades em repetir palavras que rimem, interpretar marcas diacríticas, aplicar generalizações fonéticas e pronunciar palavras com exatidão. Tendo estas crianças obstruídas as relações fundamentais de sons e símbolos da linguagem, seu transtorno torna-se difícil de corrigir, e as idéias e exercícios especialmente pensados para eles, requerem muita atenção e persistência, tanto q para o professor quanto para a criança. Em geral, os disléxicos auditivos devem delinear os seus próprios exercícios de soletrar e outras tarefas análogas. 
Id on Line Revista Multidisciplinar e de Psicologia

Id on Line Multidisciplinary and Psycology Journal

Faz-se necessário salientar, que a maioria das crianças que apresentam um quadro severo de inaptidão para a leitura, e apresentam tanto dislexia visual quanto auditiva, mesmo quando a deficiência é originalmente, uma ou outra; na dislexia profunda ou fonética, encontram-se erros do tipo semântico, alteração na compreensão do significado das palavras, com adição de sufixos e prefixos; maior facilidade para as palavras de conteúdo do que para as de função e na dislexia superficial, observam-se dificuldades dependendo do comprimento e complicação das palavras, como acontece com muitas crianças disléxicas. Em todos os casos de dislexia é importante que os profissionais da educação façam com essas crianças se desenvolvam dentro de suas capacidades, pois, "Ao mesmo tempo, o aumento da auto-estima pode se desenvolver, mesmo que aos poucos, com incentivos ao aluno de se restaurar a própria confiança, valorizar o que gosta e faz bem, ressaltar os acertos, mesmo sendo pequenos, e não enfatizar tanto os erros (GARCIA, 1998; DAVIS, 2004) apud (EVANS, 2006, p. 26).

\section{Dislexia Congênita ou Especifica do Desenvolvimento}

Esta classificação emprega-se para indicar dificuldades constitucionais e não produto de alguma incapacidade primária do cérebro, dos sentidos ou de falta de oportunidade educativa. Este quadro sugere a possibilidade de haver em atraso algum aspecto do desenvolvimento, alguma deficiência na maturação neural, que ocasiona as dificuldades na criança. Segundo Ângela Pinheiro (2002) apud (MARQUES, 2014, p.31), “a dislexia pode ter como causa as influências internas genéticas, a descoberta de um aumento de incidência de dislexia na mesma família. Existe uma hipótese de que uma anomalia genética influencie adversamente o desenvolvimento de áreas do cérebro". Paula Teles (2004) apud (MARQUES, 2014, p. 31) informa que, "nas mais recentes pesquisas sobre genética e dislexia, existem, presentemente, cinco localizações de fatores de risco, com influência na dislexia. As cinco localizações foram encontradas nos cromossomas 2p, 3p-q, 6p, 15q e 18p".

Veras (2007) A dislexia congênita simplesmente significa que a criança parece ter nascido com essas dificuldades. Supostamente grande parte de crianças incapacitada padece de problemas disléxicos que se podem atribuir diretamente à suas incapacidades primárias, como a paralisia cerebral e espinha bífida, porém o número de crianças incapacitadas que também são 
Id on Line Revista Multidisciplinar e de Psicologia

Id on Line Multidisciplinary and Psycology Journal

disléxicas, é muito menos do que se deveria esperar, se considerarmos a gravidade das disfunções físicas de que são vítimas.

Porém, aqui é focada apenas a atenção para crianças que apresentam dislexia específica do desenvolvimento ou congênito sem que haja outras irregularidades relacionadas direta ou indiretamente com as suas dificuldades de leitura, ortografia e escrita.

\section{Considerações Finais}

A dislexia é uma dificuldade de aprendizagem que faz com que muitos alunos não aprendam a ler e escrever, com isso, eles se sentem diferentes dos outros alunos e acabam sendo desestimulados. E a aprendizagem é cada vez mais prejudicada.

É importante considerar que na pesquisa desenvolvida, uma pessoa com dislexia deve ser considerada e valorizada, pois como sujeito integrante de seus sistemas psico-orgânicomental e seus conteúdos internos e manifestos acontecem de forma plena. É preciso tratá-la e "devolvê-la ao cotidiano, integrando nas suas funções: harmônica, laboriosa, produtiva, ajustada e adequada do sentimento próprio e social.

Também, deve-se considerar a prevenção, através do ponto de diagnóstico nas instituições escolares e afins, evitando sequelas e comprimentos futuros na pessoa, durante sua vida. Aqui poderá inserir incentivos do governo e partículas no financiamento de projetos à pessoa assim enquadrada; afinal, a ciência visa o bem-estar, progresso e evolução da humanidade. $\mathrm{O}$ direito à educação e a saúde são garantidos constitucionalmente a todos.

O diagnóstico precoce é imprescindível para o desenvolvimento contínuo das crianças disléxicas. Reconhecendo as características escolares é o primeiro passo para que se possam evitar dificuldade e sofrimentos, induzindo esta criança fatalmente ao desinteresse pela escola e a tudo o que estão em torno dela, gerando às vezes quadros "fóbicos" desta criança em relação às tarefas que exijam a leitura e escrita.

Uma das grandes frustrações dos pais é saber que seu filho tem problemas escolares. A maioria não sabe o que fazer como ajudar. O certo seria procurar apoio nas escolas, com os professores, mas estes também, muitas vezes, estão despreparados. Neste momento o acompanhamento de um psicopedagogo é de fundamental importância. 
Id on Line Revista Multidisciplinar e de Psicologia

Id on Line Multidisciplinary and Psycology Journal

A dislexia é uma dificuldade bastante complexa. Não é tão fácil para um leigo entender e identificar esta dificuldade de aprendizagem.

É tarefa de todos educadores, sejam eles os pais ou os professores, ter como base ética o compromisso de ver desenvolver-se dignamente e efetivamente a aprendizagem acadêmica de seus(s) educando(s), buscando novas formas de aprendizagem, novos programas e processo de ensino que possam colaborar para inclusão de crianças com dificuldades de aprendizagem (dislexia) no mundo das letras.

Precisa-se concentrar-nos em uma forma de minimizar as conseqüências causadas pela dislexia, deste modo ajudando a cada aluno a desenvolver-se não só no meio escolar, mas também no meio social. Criando cidadãos críticos e participantes. E leitores e assíduos.

\section{Referencias}

ARAUJO, Jorge de Souza. Caderno de Exercícios: algumas reflexões sobre o ato de ler, Ilhéus: Letra Imprensa, 2000.

BABERGER, J. Psicologia da Aprendizagem. São Paulo, Cultrx, 1987.

BARBOSA, J. J. Alfabetização e Leitura. São Paulo, Cortez, 1990.

BRASIL, Secretaria de Educação Fundamental. PARAMETROS CURRICULARES NACIONAIS: Língua Portuguesa - Brasília. 1997.

CASSIANO, Adriana. Monografia: O desenvolvimento da leitura e escrita. Universidade Candido Mendes. RJ 2004.

CAGLIARI, Luiz Carlos. Alfabetização e Linguística. 4 edição. São Paulo. Scipione, 1998.

COELHO, Nelly Novaes. Literatura Infantil: teoria, análise e didática. São Paulo, Ática, 1997.

EVANS, Juliana Santiago. Um Estudo sobre Dislexia, 2006. Monografia, 36 p. Ministério da Educação Universidade Tecnológica Federal do Paraná - Centro Acadêmico de Línguas Estrangeiras Modernas Curso de Especialização em Ensino de Línguas Estrangeiras Modernas - Curitiba/PA. Disponível em <http://www.calem.ct.utfpr.edu.br/monografias/JullianaEvans.pdf > Acesso em 15 de janeiro de 2016.

FREIRE, Paulo. A importância do ato de ler: em três artigos que se completam. $40^{\mathrm{a}}$ Ed. - São Paulo, Cortez, 2000. 
Id on Line Revista Multidisciplinar e de Psicologia

Id on Line Multidisciplinary and Psycology Journal

LUZ, Mônica Abud Perez de Cerqueira. Dislexia - Dificuldade Específica nos Processamentos da Linguagem, 2010. 25 p. Artigo. São Paulo. Disponível em <http://www.abpp.com.br/sites/default/files/113.pdf> Acesso em 15 de janeiro de 2016.

LISBOA, Daniela de Almeida Marques. O jogo no desenvolvimento da criança disléxica. 2014.138P. Monografia (Escola Superior de Educação João de Deus Mestrado em Ciências da Educação na Especialização em Educação Especial: Domínio Cognitivo e Motor), Lisboa/ Portugal <http://comum.rcaap.pt/bitstream/10400.26/6190/1/Daniela\%20Marques.pdf> Acesso em 15 de Janeiro de 2016.

OLIVEIRA, Marta Kohl de: Vygotsky: aprendizado e desenvolvimento - um processo sócio histórico. Scipione, 1997.

PIAGET, Jean. Psicologia e inteligência. Rio de Janeiro: Zahar, 1977.

PIAGET, Jean. Psicologia e Pedagogia. Rio de Janeiro; Forense, 1970.

REGO, Lúcia Lins Browne. Literatura Infantil: uma nova perspectiva alfabetização na préescola. São Paulo, FDT, 1988.

VERAS, Marta Castro Braga. Dislexia causa Dificuldade na Leitura e Escrita: novas possibilidades com a visão psicopedagogica, 2007. $38 \mathrm{p}$. (monografia apresentada a Universidade Regional do Cariri-URCA, como requisito parcial para a obtenção do título de especialista em Psicopedagogia). Universidade Regional do Cariri - URCA/CE.

Como citar este artigo (Formato ABNT):

NOGUEIRA, M.Z.L.; BESERRA, T.M.A.C. Dislexia: Leitura e Escrita numa Perspectiva Bibliográfica. Id on Line Revista Multidisciplinar e de Psicologia, Janeiro de 2017, vol.10, n.33, p.153-165. ISSN: 1981-1179.

Recebido: $26 / 10 / 2016$

Aceito: 26/11/2016 